\title{
LA VIGENCIA DE LA COMUNIDAD. PRÁCTICAS PARA NAVEGAR EN LA GLOBALIZACIÓN DESDE LA PERIFERIA ANDINA
}

\author{
THE VITALITY OF THE COMMUNITY. \\ PRACTICES FOR NAVIGATING GLOBALIZATION \\ FROM THE ANDEAN PERIPHERY
}

\author{
Esteban Ruiz-Ballesteros ${ }^{1}$
}

\begin{abstract}
En el ámbito andino, como en otras partes del mundo, lo comunitario se suele considerar -de forma simplificadora- sinónimo de tradición, así su pervivencia es asumida como resistencia al cambio y a la modernización. En este artículo se mantiene una tesis contraria y se muestra la vigencia de las prácticas y tácticas comunitarias para navegar en la globalización desde una comunidad costera ecuatoriana, en la periferia de los Andes: Agua Blanca (Manabí). Más allá de perspectivas estructurales, discursivas y simbólicas, el estudio se focaliza en las prácticas comunitarias cotidianas ante las políticas de conservación y la actividad turística. Sólo así podemos entrever el sentido de la comunidad frente al Estado y al mercado. Agua Blanca nos muestra el vigor de lo comunitario como emergencia contemporánea, como forma de estar en la globalización, invitándonos a pensar que las prácticas comunitarias pueden suponer innovación y vanguardia más que resistencia ancestral.
\end{abstract}

Palabras claves: comunidad, tradición, innovación, globalización, conservación ambiental, turismo.

In the Andean region, as in other parts of the world, the community is usually considered as synonym of tradition, so its existence is assumed to be a form of resistance to change and modernization. This article argues for an oppositional thesis, showing the effectiveness and vitality of communitarian practices and tactics when it comes to navigating globalization from the perspective of an Ecuadorian coastal community, on the Andean periphery: Agua Blanca (Manabí). Beyond structural, discursive and symbolic perspectives, this study focuses on everyday communitarian practices related to conservancy policies and tourist activities. This is the only way to glimpse the meaning of community in relation to the State and the market. Agua Blanca reveals the enduring effectiveness of the community as a contemporary emergence, as a way of existing within globalization, inviting us to think that communitarian practices can be innovative and cutting edge instead of mere ancestral resistance.

Key words: Community, tradition, innovation, globalization, environmental conservation, tourism.

Difícilmente se puede mantener hoy una visión de comunidad en la que primen aspectos como la homogeneidad, el igualitarismo, la simplicidad, el aislamiento y la solidaridad mecánica (Redfield 1955). Igualmente parece arriesgado considerar que la comunidad sea una mera creación discursiva, sólo comprensible desde una aproximación simbólica (Cohen 1985). Clastres (1997 [1977]) sostiene que la comunidad es la esencia de la sociedad sin Estado y que su pervivencia supone un antídoto a la homogeneización. Por tanto, su naturaleza es principalmente 'resistente', asociada a la posesión/ usufructo territorial, a una relativa independencia política y a la expresión simbólica de la diferencia/ identidad. Todo ello nos coloca ante una idea de comunidad profundamente asociada a la tradición, lejos de cualquier planteamiento dinámico, fruto de una perspectiva analítica que establece una fuerte dicotomía entre tradición y cambio, asociando a la comunidad exclusivamente con la primera.

La comunidad rara vez se encara analíticamente como alternativa, esto es: como modelo socioorganizativo que pueda implicar ventaja comparativa respecto a otras opciones, incluso como novedad. Así es difícil captar la creatividad y la astucia que pueden ser inherentes a los fenómenos comunitarios ya que éstos, en la mayoría de las ocasiones, son considerados como muestra de adaptación reactiva, sin posibilidad de constituir una forma creativa y novedosa de organización social.

1 Departamento de Ciencias Sociales, Universidad Pablo de Olavide, Carretera Utrera km 1, Sevilla 41013, España. eruibal@upo.es 
Nuestra visión de las comunidades se ha deformado hasta el punto de contemplarlas casi exclusivamente desde fuera; de ahí la preponderancia que alcanza el análisis de los discursos comunitarios. Es cierto que el deslizamiento hacia una conceptualización simbólica de las comunidades nos ha abierto un camino de comprensión, pero al mismo tiempo nos ha eclipsado paulatinamente otro: el de las prácticas. Desde una perspectiva pragmática la comunidad es un contexto de relación -entre humanos y de éstos con el medio- que adquiere sentido fenomenológico al anclarse a prácticas específicas entendidas como "actos en contexto" (Chaiklin y Lave 1993), como "artes de hacer" que implican formas de comunicarse, organizarse, sentir y actuar colectivamente (de Certeau 1990). Desde esta perspectiva resulta estéril la búsqueda de una esencia de la comunidad concebida como estructura, y asimismo banal quedarse en sus difusos límites simbólicos. Sólo las prácticas -siempre dinámicas, cambiantes- alumbrarán de manera consistente su funcionamiento real. La comunidad no existe sólo en la mente de sus miembros (Cohen 1985) sino principalmente en el proceder de éstos, en su actuar. Así lo comunitario puede ser un marco de comportamiento (Cohen 1985), factible en cualquier tipo de sociedad como antídoto al individualismo.

Pero la comunidad no es una realidad aislada en sí misma, nunca lo fue. Y en el caso americano más bien puede entenderse como una emergencia híbrida de procesos que arrancan en la colonia y que aún continúan su devenir (Arguedas 1987; Gundermann y Vergara 2009; Korovkin 2002). La comunidad está en permanente redefinición, una redefinición que hoy tiene como escenario la globalización.

La globalización ${ }^{1}$ es un fenómeno que no podemos aspirar a desentrañar aquí. Pero sin embargo es referencia obligada para comprender el devenir de la comunidad. Teniendo un carácter eminentemente técnico-económico (Ortiz 2004), la globalización propicia expresiones culturales propias en las distintas sociedades. Pero, asimismo, implica una manera particular de estar en el mundo que alimenta pautas de funcionamiento, razonamiento y representación de lo propio y lo ajeno. Esta configuración contradictoria a nivel cultural, en la que homogeneización y activación de diferencias van de la mano, nos obliga a desarrollar nuevas estrategias analíticas (Ortiz 2004) que integren estos procesos antagónicos y nos permitan comprender cómo se produce un rejuego novedoso entre lo local y lo global (García Canclini 1999). Es inútil pensar en un dentro y en un fuera para reflexionar sobre la comunidad que no puede ser concebida como una realidad contrapuesta o enfrentada a la globalización, sino más bien como expresión de ese proceso contradictorio de homogeneización-diferenciación que caracteriza nuestro mundo global. Para las propuestas teóricas que acentúan exclusivamente su vertiente homogeneizadora, las comunidades deberían ser las primeras víctimas de la globalización, pero lejos de eso algunas de ellas manifiestan su plena vigencia, como ya hicieron en otros momentos históricos. Estas comunidades en la globalización nos ponen al descubierto precisamente su carácter más íntimo y nos obligan a hacer un esfuerzo analítico para comprenderlas cabalmente.

La globalización, más que nunca, articula comunidades, Estado y mercado. Encarnada en fenómenos más concretos como el turismo o las políticas de conservación ambiental -que aúnan claramente carácter tecnoeconómico y expresión cultural-, la globalización penetra cualquier territorio imponiendo esa 'manera particular de estar en el mundo' y propiciando a su vez 'expresiones culturales específicas'. Actividad turística y políticas de conservación -como veremos en nuestro caso de estudio- combinan inextricablemente la acción del Estado y del mercado, desarmando territorios y poblaciones, trastocando globalmente formas de habitar y entender ${ }^{2}$. Sin embargo, hay comunidades que se construyen precisamente en estos mismos procesos: ¿cómo ‘navegan' en la globalización?

Aquí propongo, siguiendo a de Certeau (1990), enfocar analíticamente la comunidad como 'expresión táctica'. Para trabajar en esta línea no basta la constatación de discursos comunitarios, sino adentrarse en el análisis de las prácticas comunitarias, penetrar en qué hace la gente que vive en comunidad (de Certeau 1990; Khon 2002). Como ha expresado recientemente Kuper (2008:733): “... cuando hacemos comparaciones deberíamos prestar más atención a las prácticas que a las concepciones y símbolos".

¿En qué medida una comunidad constituye una expresión particular de organización social? En la medida en que desarrolle actitudes y acciones que le permitan seguir siendo desde el punto de vista material, es decir, como forma particular de organización socioecológica. Así, desde lo local, con forma comunitaria, frente al neoliberalismo 
pero en la globalización, se han encarnado formas alternativas de hacer agricultura (Hernández y Nigh 1998; Korovkin 1997), artesanía (Nash 1993, 2001; Stephen 2005) e incluso turismo (Ruiz-Ballesteros y Solís-Carrión 2007; Ruiz-Ballesteros y Vintimilla 2009). Todas estas actividades tienen lugar en el mercado, pero la comunidad mantiene su vigencia porque no se pliega completamente a él, no se diluye, mantiene cierta soberanía, no sólo en lo simbólico, sino fundamentalmente en lo práctico: hace las cosas de otra forma. En definitiva, se inserta en el mercado de forma táctica:

Llamo táctica a la acción calculada que determina la ausencia de un lugar propio (...) debe actuar con el terreno que le impone y organiza la ley de una fuerza extraña (...) obra poco a poco. Aprovecha las "ocasiones" y depende de ellas (...) Crea sorpresas. Le resulta posible estar allá donde no se le espera. Es astuta. En suma, la táctica es un arte del débil (de Certeau 1990:43).

De Certeau diferencia táctica de estrategia. La segunda implica un ejercicio de poder propio, la primera es un ejercicio desde la asimetría pero no puede confundirse con una mera reacción causal. Una de sus características definitorias es precisamente la creatividad. Aquí reside el valor analítico del concepto. La táctica va más allá de la mera resistencia en tanto en cuanto es creativa y termina escapando en cierta medida a lo dispuesto, a lo hegemónico. Desde esta perspectiva podemos entender que la comunidad sea una alternativa para navegar en la globalización: no la niega, sino que la integra tácticamente. De ahí que la comunidad, mediante prácticas específicas, se pueda reafirmar ante el Estado y el mercado evitando la completa homogeneización que temía Clastres. Hay un modo comunitario de vivir la globalización que hace que la comunidad no sea contradictoria con la globalización sino que forme parte de ella, pero sin disolución, sino más bien reafirmándose en ella tácticamente.

Para comprenderlo quizá tengamos que dar un cierto giro a nuestra concepción de comunidad. En su configuración más simple bastaría considerarla como un conjunto de prácticas articuladas, como el despliegue de mecanismos relacionales precisos para el funcionamiento social (Brint 2001; Walsh y
High 1999). Lo comunitario sería un contexto difuso que dependería de su configuración concreta en cada momento y cada lugar. En ese sentido tendríamos que hablar de comunidad como proceso (Ruiz-Ballesteros 2009), como proceso de comunitarización. Es ahí donde puede sustanciarse efectivamente una forma de navegar en la globalización: la comunidad como forma de hacer.

En este sentido y como conjunto de prácticas, la comunidad expresa una "filosofía de los débiles" que procura un balance entre libertad y seguridad (Bauman 2001). Ellos no pueden permitirse que los valores de un exclusivo individualismo meritocrático queden por encima de la obligación de compartir; son, por tanto, "individuos de jure que no son capaces de practicar la individualidad de facto" (Bauman 2001:71). Para hacer factible un contexto relacional de estas características la comunidad implica un "entendimiento común" y un "fundamento epistemológico" (Bauman 2001) practicado y alimentado en contextos colectivos.

En gran medida, la base de este fundamento epistemológico reside en la práctica de la reciprocidad (Temple y Chabal 1995; Temple 2003a, 2003b) que alimenta los lazos sociales y anima la integración social previniendo la exclusión. La reciprocidad promueve lo común. Por su parte, el intercambio, como forma alternativa, supone una liberación de esos lazos sociales que patrocina la reciprocidad. El intercambio se concentra en los propios objetos que circulan (en vez de en los lazos sociales que éstos pudieran generar) y en las personas como individuos. Se anima así la acumulación antes que el don (Temple 2003b). Reciprocidad e intercambio, como dos marcos de relación entre humanos y de éstos con el medio ambiente, dan lugar a dos economías complementarias. Sin embargo, no cabe pensarse que la comunidad sea el campo de la reciprocidad, ni situar fuera de ella el campo del intercambio. Esto sería una simplificación estéril. Reciprocidad e intercambio conviven en tensión al interior de las comunidades (Temple 2003b). No obstante, desde que se viene desarrollando como forma única de concebir las relaciones entre los humanos (alimentado por la globalización), el intercambio socava el espacio de la reciprocidad. La comunidad supera esa contradicción reciprocidad-intercambio a partir de interfases (Temple 2003b) que permiten convertir marcos de intercambio en contextos de reciprocidad, evitando así la erosión de ésta. Parte 
de las prácticas comunitarias vienen precisamente a desarrollar esta función y es en ellas donde hemos de encontrar la vigencia de la comunidad como expresión táctica (de Certeau 1990) que hace posible que el intercambio no se erija en referente único de la relación social (Temple 2003a) propiciando la conformación de un ámbito de entendimiento común (Bauman 2001). Estudiando los fenómenos comunitarios desde esta perspectiva podemos llegar a comprender cabalmente su vigencia en la globalización.

\section{Agua Blanca, una Experiencia Comunitaria en la Costa Ecuatoriana}

En Ecuador, 'comunidad' es una noción de profundo sentido histórico, jurídico, administrativo y socioorganizativo. Con raíces en encomiendas, huasipungos y haciendas, las comunidades ecuatorianas se comienzan a constituir formalmente a partir de la Ley de Comunas de 1937 que pretendía restituir la vinculación entre los pueblos indígenas, los campesinos y sus territorios. No es ajeno tampoco el devenir comunitario a los distintos episodios de reforma agraria en el país, ya que la asignación de tierras corría con frecuencia paralela a la constitución administrativa de comunidades que garantizaban su gestión colectiva. La actual Ley de Organización y Régimen de Comunas de 2004 define la organización, el gobierno y las facultades de las comunidades insertándolas como último escalón en la organización político-administrativa del Estado (Estado, provincias, cantones, parroquias, comunidades). Las comunidades poseen frecuentemente bienes colectivos (tierras) y tienen un sistema de decisión radicado en la asamblea que elige anualmente al cabildo, órgano colegiado de gobierno y administración. La reciente potenciación de lo comunitario en el Ecuador coincide con el auge de los movimientos indígenas en los años 90 y la plasmación de muchas de sus reivindicaciones en las constituciones de 1998 y 2008. Por tanto, y tal como ocurre en otros países latinoamericanos, no podemos entender la comunidad sin considerar el papel del Estado en su devenir (Gundermann y Vergara 2009).

Sin embargo, la conformación específica de cada comunidad añade heterogeneidad al mero marco jurídico-administrativo que las regula. Por eso se hace necesario aproximarnos a la génesis de cada una para comprender cabalmente su dimensión socioorganizativa concreta.
Agua Blanca es la localidad que sustanciará nuestra reflexión. Situada al sur de la provincia de Manabí, a unos doce kilómetros del Pacífico, en el valle del río Buenavista, sus 8.000 ha presentan una notable relevancia ecológica y cultural (incluye bosque seco y nublado tropical, así como abundantes restos arqueológicos de la cultura manteña). $\mathrm{La}$ habitan unas 260 personas integradas en una densa red de parentesco, circunstancia que no se traduce en homogeneidad interna. Los aguablanquenses manifiestan y expresan intereses individuales y grupales particulares y además presentan una cierta diferenciación en cuanto a renta per cápita y participación en actividades productivas (Ruiz-Ballesteros 2009). El funcionamiento de la comunidad denota tanto profundos conflictos de intereses como capacidad para generar consenso y acción colectiva (Ruiz-Ballesteros 2009). La edad y el género son criterios básicos de diferenciación y segmentación sociopolítica aunque están siendo afectados por agudas transformaciones.

Los orígenes de este contexto comunitario arrancan a fines del siglo XIX cuando, en una zona periférica y prácticamente despoblada de Manabí, se constituye la hacienda Agua Blanca. Esta hacienda atrajo a la primera generación de los actuales pobladores de la comunidad, de orígenes muy heterogéneos, y que como jornaleros trabajaron para ella a lo largo de 75 años en diferentes actividades (recolección de tagua, ganadería, cultivo de café, tala de madera, producción de carbón...). El régimen de hacienda implicaba una total dependencia y dominación habida cuenta del control que se ejercía sobre el empleo, el agua (muy escasa) y la producción-distribución de alimentos.

A mediados de los sesenta del siglo XX la hacienda sufrió una profunda crisis y se declaró en bancarrota. Ya en 1964 los jornaleros y sus familias se constituyeron formalmente en comunidad asegurándose el control de 4.000 ha de bosque seco liberados en un episodio de reforma agraria. Sin embargo, este terreno no garantizaba la subsistencia ya que no daba acceso al agua. Para permanecer en el territorio se necesitaban las tierras productivas de la hacienda y así se comienza a desarrollar una primera movilización colectiva para hacerse con su control. No obstante, esta aspiración se vio definitivamente truncada cuando a finales de los años 70 se crea el Parque Nacional Machalilla (PNM) que asume la propiedad de la antigua hacienda y se propone, aplicando estrictos criterios de conservación 
ambiental, la deportación de la población que habita en su interior. A partir de ese momento, el PNM persigue sistemáticamente a los habitantes de Agua Blanca prohibiéndoles la caza, la tala de madera y la producción de carbón vegetal, sus actividades principales de subsistencia. A la comunidad sólo le cabe la lucha contra el PNM o la migración.

Entre mediados de los sesenta y mediados de los ochenta se asiste a un periodo sumamente conflictivo, basado en la resistencia de los aguablanquenses y en la impotencia del PNM para deportarlos, que termina con un acuerdo tácito por el cual los comuneros cambian drásticamente sus formas de explotación de recursos, abandonando progresivamente las actividades de mayor impacto ambiental (desaparición de la caza y tala de madera y reducción progresiva de la ganadería y el carboneo) y orientándose hacia el turismo comunitario. Por su parte, el parque entrega en usufructo las 4.000 ha de la antigua hacienda a los comuneros, permitiéndoles el cultivo de subsistencia y el desarrollo turístico, amén de otras prerrogativas que aseguran a la comunidad un gran nivel de autonomía interna en la gestión del territorio, cuyos recursos serán de su uso exclusivo y se gestionarán colectivamente, todo ello garantizado por el propio parque.

Como puede comprobarse, las partes en conflicto cambiaron sustancialmente sus pretensiones de partida y finalmente la comunidad experimentó un fuerte proceso de cohesión interna así como de transformación de su cotidianidad. En todo ello tuvieron un papel capital los arqueólogos que durante más de una década habían desarrollado distintas campañas de excavación en la zona, actuando como mediadores entre la comunidad y el PNM, y asimismo como catalizadores de la patrimonialización del territorio y de su modelo de desarrollo local (McEwan, Silva y Hudson 2006). Es a partir de este momento que la comunidad toma consistencia como contexto organizativo: los jornaleros de lógica individualista y dependientes del empleo en la hacienda se habían convertido en 'propietarios' colectivos de un territorio y responsables de su gestión.

La génesis de esta comunidad se explica, por tanto, por su capacidad de adaptación creativa a las políticas de conservación ambiental y por el desarrollo exitoso de una forma de turismo de base local (Ruiz-Ballesteros 2009). Ambos fenómenos se entienden aquí como expresiones inequívocas de la globalización sobre el territorio. Son fruto de tendencias tecnoeconómicas de fuerte implicación cultural ya que conllevan tanto una remodelación del sentido del propio territorio para sus habitantes (a través de su patrimonialización natural y cultural) como del desarrollo de una nueva actividad económica desconocida anteriormente. Este proceso comporta los dos ejes culturales que señala Ortiz (2004) para definir la globalización: el despliegue de una forma homogeneizadora de estar en el mundo (a partir de la naturalización del medio, por ejemplo), y al mismo tiempo el desarrollo de formas particulares de conceptualizar y organizar la actividad turística, como veremos más adelante.

La clave de la adaptación creativa a la que nos referimos es la autoorganización social, sólo entendible desde una progresiva comunitarización de la vida local. Agua Blanca se ha hecho comunidad de manera efectiva desde los años ochenta del siglo XX, no hay por tanto mayor ancestralidad en su configuración, antes de eso era poco más que un agregado de jornaleros de orígenes diversos al servicio de una hacienda. En su devenir es crucial la transformación de la estructuración social interna así como su forma de inserción en el medio, ambos procesos en directa relación con la presión externa; pero, al mismo tiempo, la comunidad ha sido capaz de imponer su presencia contra la voluntad del parque y conseguir reconocimientos y exclusividades sobre el uso y gestión de distintos recursos. Es por ello precisamente que hablamos de "adaptación creativa" para explicar su devenir y de "estructura emergente" para comprender su configuración interna.

Los aguablanquenses han desarrollado un discurso simbólico que justifica su comunidad a partir de la lucha por la posesión del territorio. Este discurso ha cristalizado en dos procesos paralelos. Por un lado, la patrimonialización tanto de la naturaleza como de los restos arqueológicos manteños que salpican su entorno. La comunidad ha configurado una nueva forma de relación con el territorio a partir de su consideración como patrimonio natural y cultural, esto es: el entorno se conceptualiza a partir de recursos nuevos (de la madera o el carbón al aprovechamiento turístico del paisaje, la fauna o las ruinas arqueológicas).

Por otro, la etnogénesis del pueblo manteño, reconocido oficialmente por el Estado ecuatoriano en 2005 (Hernández-Ramírez y Ruiz-Ballesteros 2011), juega un papel decisivo en la apropiación 
territorial. Junto a otras comunidades vecinas, Agua Blanca conforma el pueblo manteño, justificado en derechos sobre el territorio y en el origen cultural común con base en los hallazgos arqueológicos de la región. Este reconocimiento oficial otorga un estatus legal y político muy relevante para la comunidad dentro de su parroquia y cantón al suponer no sólo un claro distintivo sino también una garantía de base cultural sobre la posesión y uso del territorio. Esta circunstancia resulta táctica común en el ámbito andino (cfr. McNeish 2002:244).

No es difícil imaginar cómo el negocio turístico es en sí mismo un contexto simbólico de reafirmación comunitaria: para los turistas la figura del indígena y la comunidad son alicientes exóticos de la propia visita. Asimismo, el estatus de comunidad indígena es primordial para atraer intervenciones externas, sea del propio Estado, sea de las organizaciones internacionales. Indígenas y comunidades son objetivos prioritarios de la cooperación al desarrollo (de Hart 2009); en este contexto el discurso comunitarioindígena se produce y reproduce también al calor de las inversiones y de la sensibilidad internacional (Niezen 2003).

Asimismo, desde 1992, Agua Blanca celebra el festival de la balsa manteña, un ritual en el que la comunidad visita las capitales de su parroquia y cantón, disfrazados de manteños y reivindicando la capitalidad ancestral que le atribuyen las investigaciones arqueológicas. Hoy esta celebración es una clara expresión de la comunidad y de sus límites simbólicos (Cohen 1985).

Si nos fijamos bien, todas estas circunstancias tienen lugar en espacios liminales: reafirman límites comunitarios ante turistas, ante ONG o ante las demás localidades de la región. Tienen así fuerza y vigencia ante el mercado y el Estado, reafirman la existencia de la comunidad. Como expresión comunicativa, su lógica forma parte de los discursos globalizados. La comunidad se inserta así a un contexto global complejo que tiene en la diversidad cultural y la protección ambiental dos de sus pilares discursivos básicos. Esos son también los contenidos principales del discurso comunitario:

somos descendientes de indígenas y protegemos el medio ambiente desde nuestra legitimidad como comunidad que ocupa su territorio ancestral, por eso tenemos derecho a explotarlo turísticamente (Paul, líder comunitario).
Conservación ambiental y turismo son las dos formas más contundentes en las que lo global penetra lo local en Agua Blanca, la defensa de la territorialidad y la reclamación de una exclusividad en el mercado turístico son las respuestas comunitarias. Pero ¿es suficiente su constatación para comprender la existencia de esta comunidad?, ¿explicamos a través de lo simbólico cómo funciona realmente?, $¿$ entendemos el sentido y vigencia de lo comunitario? Su fortaleza y réditos prácticos son evidentes, pero es lugar común para comunidades de muchas áreas geográficas. El discurso de la comunidadindígena-que-reclama-un-territorio no parece óbice para suponer un espacio social particular, y menos aún un ejercicio alternativo al Estado o al mercado. ¿Qué es la comunidad entonces?

\section{La Comunidad como Práctica}

Para comprender Agua Blanca, como comunidad, no basta con su verificación territorial, política y simbólica, sino que debemos investigar las formas íntimas de su producción y reproducción social. Es preciso imaginar la comunidad no como un contexto exclusivamente resistentesimbólico-discursivo sino como una táctica fundada en prácticas. Esas prácticas encaran fenómenos globales como el turismo y la conservación ambiental, cuyo desarrollo afecta profundamente a las pautas de reciprocidad y de intercambio, así como a las posibilidades de sustentar un 'entendimiento común' en el seno de la comunidad. La vigencia de ésta depende así de su capacidad tanto para generar interfases que conviertan relaciones de intercambio en reciprocidad, como para alimentar espacios comunicativos.

La asamblea, por un lado, y el principio de la rotación de oportunidades y obligaciones, por otro, serán los contextos prácticos sobre los que centraremos nuestro análisis. Su relevancia en el funcionamiento de las comunidades andinas está fuera de duda y ambas prácticas sintetizan el sentido comunitario mostrando las claves para comprender cuál es la forma en que lo global se convierte en local. En definitiva, nos muestran qué es realmente la comunidad desde dentro.

\section{Asamblea}

En el ámbito andino, la comunidad es -en gran medida- reflejo de sus asambleas. El carácter regular 
o no de éstas, la forma en que se tratan los asuntos, la asistencia, el tono de la comunicación, el nivel de los acuerdos y desacuerdos..., todo ello marca qué es una comunidad. La asamblea es tanto un retrato como un termómetro, en ella tiene lugar la construcción colectiva de conocimiento y acción, actúa como filtro de lo que viene de afuera y resulta crucial para la socialización de los jóvenes. Es uno de los espacios en el que se forja el entendimiento común y la comunidad se encarna como "fundamento epistemológico" (Bauman 2001).

En Agua Blanca, el primer domingo de cada mes, a partir de las nueve de la mañana, hay asamblea. Durante los tres años de mi trabajo de campo intermitente, jamás asistí a ninguna que comenzara antes de las diez y que durara menos de cinco horas. El presidente y los miembros de la directiva barren la casa comunal y preparan las sillas. Los socios y socias acuden con su ropa de domingo. Las asambleas ordinarias reúnen habitualmente a la mitad de los socios $^{3}$, sin embargo las extraordinarias (asuntos relevantes o elecciones) congregan a la práctica totalidad. A los más jóvenes les gusta agruparse al fondo del salón, todos juntos provocan el juego y la broma. Las mujeres van acompañadas por sus hijos más pequeños que corretean y juegan. Durante la sesión lo serio y lo jocoso se solapa, la casa comunal es un constante entrar y salir de gente.

La asamblea es el foro de la comunidad, el espacio oficial de intercambio de información, de análisis colectivo y de toma de decisiones. Para los comuneros un asunto se hace verdaderamente común si ha pasado por la asamblea. Ésta tiene sus tiempos, sus formas, su tono, su proceder particular; es un espacio al que se va con opiniones ya conformadas pero en el que se forman otras nuevas. Aquí reside parte de su trascendencia.

La asamblea es el órgano de gobierno sobre el territorio, por tanto de expresión de su posesión, de ahí su relevancia directa sobre los asuntos ambientales. En esta comunidad no hay propiedad privada alguna ni uso exclusivo de recursos. De este modo, la construcción de casas, la cesión de terrenos para el ganado, la necesidad de recursos del bosque y la regulación sobre su uso, las iniciativas de trabajo colectivo, el control sobre los productos que salen de la comunidad, la gestión del agua potable y de riego, el negocio turístico... todos son asuntos que deben ser debatidos y aprobados en asamblea que funciona así como válvula autorreguladora de la comunidad.
Esta función de gobierno de la asamblea fue ganada poco a poco sobre las competencias del parque nacional y -como se ha señalado ya-en veinticinco años los aguablanquenses han experimentado una transformación radical. Efectivamente su forma de estar en el territorio ha cambiado y paralelamente han construido una estructura de funcionamiento comunitaria que antes no existía. La asamblea, con sus formas y funciones, es una de sus piedras angulares y esa transformación socioecológica se ha producido en su seno y en virtud de las prácticas que conlleva.

La asamblea ha sido el contexto de la autorregulación, el espacio en el que los aguablanquenses han dejado de ser cazadores, taladores y carboneros, para convertirse en guías turísticos y cultivadores. Más allá de la presión externa, han sido los sistemas de control interno los que han propiciado el cambio. Una vez reconocido el usufructo y autogobierno sobre las 8.000 ha reclamadas como territorio comunitario, son las prácticas asamblearias las que sirven de medio para configurar a la comunidad como tal, por eso es fundamental aproximarse a su funcionamiento, sobre todo a las formas en que se producen las decisiones y la manera en que se resuelven los conflictos.

En la asamblea no hay decisión sin debate, y este con frecuencia se llena de argumentos y contraargumentos, comparaciones y analogías. La presidencia expone el asunto y calla. Se hace el silencio en la reunión por unos minutos hasta que alguien pide la palabra y crea una argumentación. A continuación otro puede hacer lo propio, sólo que en dirección argumentativa distinta. No es fácil que se perfilen posturas nítidas porque las intervenciones parecen erráticas, saltando de unas perspectivas a otras, e incluso de unos temas a otros; a veces con momentos muy largos de silencio. Cuando parece que se avanza en la reflexión se vuelve al principio. El proceso implica una decantación muy lenta. La construcción de un planteamiento colectivo se toma su tiempo. A veces el asunto queda abierto y será retomado en otra sesión. Otras veces sí se decide, pero antes de eso, sobre todo cuando hay posturas encontradas, es necesario que la asamblea se pronuncie. Ese pronunciamiento no se limita a una votación simplificada entre las opciones a elegir. Es más complejo. Se exige un pronunciamiento individual, explícito y razonado. Este proceder implica tiempo, y a veces significa una vuelta a la fase de análisis previo, e incluso a retomar desde el 
principio todo el debate. Sólo así se entiende que la comunidad decide. Si no se alcanza una visión lo suficientemente común, el tema queda aparcado para otra sesión. No se concibe la mayoría como tal, pero tampoco el consenso ${ }^{4}$ absoluto; se sigue una lógica más difusa e intuitiva: "cuando el asunto esté maduro" me han explicado distintos presidentes. Se tolera un pequeño disenso pero no se aspira a la unanimidad. Cuando el asunto es la creación de una norma, las prevenciones, las demoras y el tiempo se dilatan aún más, durante varias sesiones. Hay cambios normativos que se han tomado meses. La asamblea no persigue un funcionamiento ágil, sino sólido. De esta manera he asistido a la regulación del ganado vacuno, a la reorganización del riego de las huertas, o a la delimitación de zonas para el carboneo. En definitiva, a la regulación local de las políticas de conservación.

La asamblea es asimismo el órgano de vigilancia sobre las actividades extractivas y de control sobre la injerencia de forasteros. Actúa así como núcleo de gestión de la información. Cuando tiene lugar un suceso relevante (alguien ha realizado una actividad prohibida, se ha visto a extraños merodeando por el territorio de la comunidad...) éste se convierte rápido en la comidilla de los distintos foros de la vida cotidiana -la novedad es algo muy estimado-. Se construyen diversas versiones que transitan por las conversaciones y si el asunto es suficientemente notorio llegará finalmente a la asamblea, donde se construye una versión o versiones admitidas, cosidas con los retales que a ella llegan. Así el devenir se va haciendo objeto de análisis y reflexión. Por eso la participación en la asamblea es una obsesión para muchos: "es la base de nuestra organización" (Hugo, guía turístico). No habrá comunicación comunitaria consistente sin asamblea, ella es el gran espacio comunicativo, a modo de corazón de la comunidad, órgano vital que vivifica el funcionamiento colectivo en el 'cara a cara' público. La asamblea es así uno de los fundamentos del conocimiento y la acción colectiva, ilustrando el carácter epistemológico de la comunidad (Bauman 2001). La dinámica comunitaria es muy distinta de las dinámicas que en otros contextos sociales construyen lo colectivo. El caso de Agua Blanca muestra cómo el sentido del territorio y de la conservación se construye mediante prácticas asamblearias desarrolladas tácticamente (de Certeau 1990).

En la comunidad se chismorrea y critica a los demás, eso no se pretende evitar aunque se censure.
Lo que la asamblea significa -como espacio inexistente en otros contextos- es la oportunidad de hacer públicas esas opiniones, de contrastarlas, de buscar explicaciones y enderezar comportamientos que parezcan erróneos. Todo ello es de importancia capital para comprender cómo la conservación se ha llegado a convertir en un asunto comunitario, asumido y practicado como propio.

La asamblea es el lugar en el que se orientan la acción y el pensamiento, una plataforma táctica, ética y estética. Evidentemente no es el único espacio en el que se construyen discursos que representen la realidad, pero sí es el espacio "oficial" para que la realidad sea comunitaria. Como espacio teatralizado sirve para hacer explícitas las dudas, críticas o reproches a los otros, lo que siempre resulta conflictivo para las relaciones sociales. Los problemas si se verbalizan en público adquieren otra dimensión.

He presenciado acusaciones directas por extralimitación en derechos de uso, por hacer carbón en zonas no recomendadas, por despilfarro de agua, o por realizar actividades turísticas sin permiso de la comunidad... Se trata de interpelaciones directas, señalando, cuando se conoce, a sus protagonistas, o implicando una autoinculpación o justificación de éste. Pronto quise imaginar disputas permanentes, familias enfrentadas, personas que no se hablaban... Supuse que tras estas denuncias o quejas se esconderían indicios de esas relaciones enquistadas... Pero al cabo del tiempo y a pesar de mi incredulidad, uno de los interpelados me reconoció que

... a veces en la reunión se discute alguna cosa dura pero no quedamos enemigos. Se aclaran las cosas, para eso son las reuniones. Saben que yo estoy haciendo una cosa mal, pues me la dicen. Si no es así yo digo que no. Si es así pues tengo que aceptarlo porque me dicen la verdad... (Daniel).

Esta es una de las claves para comprender la práctica de la comunidad, el papel de la asamblea y de las relaciones comunitarias. Esto evidentemente no significa que no haya enfrentamientos, conflictos y disputas, sino que en el marco de las relaciones personales se lidia con ellos de forma particular: la comunidad no puede permitirse fracturas que la debiliten, lo cual no quiere decir que no exista conflicto. En este sentido, la asamblea es una especie de interfase que articula explícitamente lo individual y lo colectivo, y sin negar ninguna de las 
dos dimensiones, integra su inherente contradicción (Temple 2003a).

La asamblea es una medida de las relaciones dentro de la comunidad, incluida la jerarquización por sexo y edad en la que aquí no nos hemos detenido. En ella cristaliza el tono de la comunicación, se explicitan los mecanismos de control y regulación en el uso del territorio, por tanto muestra la práctica de lo comunitario en uno de sus aspectos fundamentales: la asunción de una perspectiva de conservación desde lo local. En la asamblea lo discursivo queda sólidamente articulado con lo práctico; las formas de la comunicación y sus contenidos son inextricables, si a esto unimos su carácter de interfase individuo-colectivo, podemos comprender en qué medida la práctica asamblearia constituye un recurso táctico para traducir a lo local la lógica global de la conservación. En la asamblea se evidencia esa "filosofía de los débiles" que no pueden permitirse el gobierno exclusivo de la lógica individualista (Bauman 2001).

\section{Rotación}

En Agua Blanca convive un universo marcadamente individualista -común en el mundo globalizado-con la posesión comunal del territorio y de todos sus recursos. Por tanto, la construcción de la comunidad depende de la articulación de los intereses y compromisos colectivos, con los deseos y expectativas individuales. Ahí surge la rotación como política de asignación de oportunidades y obligaciones individuales con criterio colectivo. La rotación como expresión de reciprocidad (Temple 2003a) para compensar la hegemonía de las relaciones de intercambio.

La rotación obedece a una lógica de reparto. Pero le subyace una filosofía más general de equitatividad e igualdad de oportunidades que tiene más en cuenta a las familias que a los propios individuos. Si bien en el conjunto andino la rotación tiene un origen evidente en las estrategias para organizar el acceso a los recursos (agua y tierra) (Arguedas 1987) o la circulación de cargos y dones (Michaux et al. 2003), en Agua Blanca se expresa también en otros ámbitos más novedosos.

En Agua Blanca esta lógica impregna gran parte de la gestión comunal determinando sus prácticas. Cuando a la comuna llega un proyecto de intervención externa al que se asocia empleo (construcción de infraestructura, repoblación forestal...), hay que decidir quién participará en él. Una vez se conocen la necesidad de personal y el tiempo de trabajo, los dirigentes negocian con la organización o institución correspondiente el carácter rotatorio que tendrá ese empleo ofertado. Se establece el número de miembros de la comunidad que podrían implicarse rotatoriamente y los requisitos preferenciales para asignar personas concretas en virtud de las circunstancias que atraviesan sus familias.

El objetivo de esta práctica es múltiple. Por un lado se garantizan la transparencia y el beneficio equitativo sobre las oportunidades que vienen de fuera. Por otra parte, se procura que las familias que pasan por una situación económica más comprometida tengan preferencia. Además, se refuerza el papel político de la comunidad. Y, por último, se intenta hacer política ambiental. Esto es, si se trata de un momento especialmente intenso de producción de carbón se buscará que los carboneros sean los principales destinatarios de la oferta para que así "dejen más tranquilos a los árboles del valle" (Cléber, dirigente). De esta forma la rotación es un mecanismo de autorregulación socioeconómicopolítico-ambiental que además potencia el 'lazo social' (Temple 2003a) en tanto en cuanto se constituye como actitud de unos comuneros con respecto a otros. La rotación constituye así una expresión de la reciprocidad.

Es importante que comprendamos que la rotación es una estrategia que va más allá de la simple asignación de oportunidades, más bien es una lógica que impregna la práctica comunitaria. No implica que en la comunidad sus socios se consideren iguales o que pretendan serlo, no debemos sospechar ingenuidad en este sentido. Sino más bien que las oportunidades se repartan de forma equitativa y que sirvan para procurar más igualación económica en vez de abrir mayores diferencias: la desigualdad no será promovida desde la comunidad. Este es el mensaje que esconde la rotación. Las estrategias económicas de los comuneros son múltiples, se constatan más de una veintena de actividades productivas distintas y su complementariedad es la norma. Las familias tienen cubierto un umbral de subsistencia mínimo en base a la producción y recolección para el autoconsumo, pero los ingresos monetarios por persona/año entre unidades domésticas presentan diferencias significativas (en ocasiones del doble). Por tanto, no estamos en una comunidad de iguales, sin embargo, la política comunitaria persigue que las diferencias no se agranden, y la rotación es la 
principal herramienta para ello. De esta forma, la rotación, en tanto que práctica, puede entenderse como una interfase que convierte la filosofía de intercambio en práctica de reciprocidad. Esto es posible porque la rotación descansa sobre la asunción de "un límite al provecho propio" (Temple 2003b:48-49) y posterior asignación equitativa de oportunidades. Así, el acceso a estas oportunidades de empleo está tamizado por unas prácticas que no se encuentran fuera de la comunidad donde prevalecen exclusivamente el espíritu de intercambio y la lógica individualista.

La rotación encierra así una dimensión profunda de la práctica comunitaria, pero también revela una tensión inherente. El igualitarismo, por un lado, y el control sobre las diferencias, por otro, convergen en esta estrategia de asignación de oportunidades. Pero este camino no está exento de contraindicaciones y paradojas. La rotación es una encarnación de la reciprocidad, en este caso sobre las oportunidades, pero ubicadas dentro de un sistema global en el que no prima precisamente la reciprocidad. La rotación es una tendencia a contracorriente, de forma parecida a como lo es la propia asamblea, y es curiosamente en el sistema de organización de la actividad turística donde podremos acercarnos más a su sentido profundo.

El turismo comunitario (Ruiz-Ballesteros y Solís-Carrión 2007; Ruiz-Ballesteros et al. 2008) en Agua Blanca implica la gestión colectiva de las visitas que los turistas hacen al territorio comunitario por espacio de unas cuatro horas. Unos diez mil visitantes llegaron a la comunidad en 2008 , no hay apenas pernoctaciones. Un pequeño museo, las ruinas arqueológicas, una laguna de agua sulfurosa y el bosque seco son los atractivos turísticos; y los aguablanquenses trabajan autoorganizados como guías. En total son treinta, cada uno representando a una familia, y divididos en tres equipos de diez miembros que trabajan en el turismo diez días de cada mes exclusivamente. Esos guías acompañan a los grupos de turistas por la comunidad y se dedican al mantenimiento de toda la infraestructura turística local. De ahí sacan una retribución que supone de manera general el 50\% de sus ingresos totales y casi un $30 \%$ de los ingresos del conjunto de la comunidad (Ruiz-Ballesteros 2009).

El comité que organiza el turismo comunitario persigue la igualdad en oportunidades, capacidades, desempeño y habilidades entre sus miembros..., y los beneficios se reparten también a partes iguales entre ellos. La rotación y el azar ordenan el trabajo del grupo como garantes de esa igualdad. Sin embargo, dentro de ese comité las diferencias son evidentes: hay algunos guías excepcionales, mientras que otros son más experimentados en tareas de mantenimiento (albañilería, carpintería); personas que se caracterizan por su exquisita expresión y trato profesional con los turistas, mientras a otros les faltan habilidades en este sentido; e incluso miembros con solvencia para la escritura y la contabilidad junto a algunos que apenas saben leer y escribir. No obstante, todos se ocuparán de todo tipo de tareas a lo largo de sus diez días de trabajo mensuales. Las capacidades diferenciales, de las que todos son conscientes, no entran en concurso a la hora de organizar internamente ni el comité en su conjunto ni cada uno de los grupos de trabajo en particular. Se encarna así la fobia a la meritocracia individualista que Bauman (2001) atribuye al espíritu comunitario. Además, esta táctica propicia notablemente la cohesión, como hace cualquier práctica de reciprocidad (Temple 2003a): evita los resquemores, los favoritismos, hace que todos aprendan y se adiestren en todas las tareas posibles; mas lesiona la competitividad del grupo porque el conjunto de su trabajo lo conforma la media de las habilidades de sus miembros y no la suma de sus habilidades diferenciales.

Además, el sorteo y la rotación es el criterio exclusivo para la constitución de los grupos de trabajo y la asignación de tareas, lo que de hecho separa irremediablemente a los miembros más afines, al tiempo que la propia rotación interna dentro de cada grupo de trabajo hace que se tenga que compartir tarea tanto con amigos y parientes como con compañeros con los que no se tiene mucha relación ordinaria. Se genera así un curioso espacio que difumina redes bien establecidas y propicia un contacto intenso de manera generalizada. Forzosamente todos con todos, para hacer de todo...

La determinación de los dirigentes del propio comité turístico sigue una lógica análoga, haciendo del cargo antes un servicio que una expresión de poder (Michaux et al. 2003:100). El comité precisa de dirigentes que coordinen y organicen, también requiere de líderes que cristalicen nuevas ideas, que den forma a las necesidades y sus satisfacciones, que innoven, que desarrollen habilidades diferenciales. Estas posiciones de liderazgo chocan frontalmente con la política interna de igualitarismo y de rotación. Por eso el comité es también, y ante todo, un espacio de aprendizaje para todos, también 
para los líderes. La tensión entre el destacar y el ser uno más se abre a cada paso. Hay personas, e incluso grupos de trabajo, con más iniciativa que otros. Mas esos mismos grupos se forman por azar, en el sorteo anual. No son equipos que se procuran equilibrados habida cuenta de las personalidades y habilidades de sus miembros, no están pensados como equipos racionalmente formados para que den el máximo rendimiento. Surgen del azar en un sorteo anual. No importa lo extraña que resulte la agrupación resultante. Nadie podrá quejarse de los criterios ni de las decisiones para formar los grupos de trabajo. El azar evita discusión y polémica, a pesar de que reste eficacia. Aunque ¿de qué eficacia cabe hablar?

Esta es la lógica que gobierna la organización del turismo en Agua Blanca. Es la que los propios miembros del comité se han dado, la que prefieren por el momento. Dentro de los grupos se precisa que cada mes haya un tesorero (que guarda el dinero recaudado a lo largo de los diez días de turno) y un secretario que va anotando las incidencias diarias. Esos cargos se hacen también rotar; no se eligen. Con determinaciones de este tipo se está profundizando en una obligatoria confianza mutua.

El comité que organiza el turismo comunitario funciona como vanguardia comunitaria. Todas las características de ésta se escenifican exageradamente en él. Su organización es una suerte de emergencia comunitaria que llega más lejos de lo que la propia comunidad puede. La sociabilidad, la comunicación, el acuerdo y el desacuerdo, el humor y la tensión, la rotación y las habilidades diferenciales, el igualitarismo y los liderazgos, la relajación y el reglamento..., en definitiva todas las tensiones inherentes a la práctica de la comunidad se convierten en la actividad turística en tácticas que se intensifican y agudizan, que llegan quizá hasta el punto máximo de su elasticidad. Si la comunidad es una unidad de gestión del territorio y los recursos, el comité turístico, construido sobre ella, es una unidad de gestión del trabajo. Parte de su naturaleza reside en esta capital circunstancia y en cómo se reparten los beneficios obtenidos. No olvidemos que los ingresos que se derivan del turismo comunitario son los más importantes de la comunidad y que una parte se dedica a financiar la propia gestión comunitaria general. Como es fácil imaginar, las reuniones de este comité acentúan notablemente las características de las propias asambleas.
En la organización del trabajo turístico, el incremento de la distancia entre los más hábiles y los menos podría mejorar el desempeño y la eficacia colectiva, pero minaría la cohesión interna por diferenciación funcional. Una y otra tendencia tiene sus beneficios y sus desventajas. Un dilema sin solución que genera tensión, pero que quizá está alumbrando una forma de eficacia sólo entendible desde la perspectiva comunitaria. La gestión de este tipo de tensiones es posible mediante marcos normativos tan estrictos como flexibles, aplicados tras su interpretación en asambleas con presencia de los interesados. Así es como se entiende la profusión de normativas y reglamentos en la comuna y su posterior aplicación diferencial dependiendo del contexto y el momento. Lo que pudiera calificarse como falta de rigor, no es más que una táctica de autogobierno cotidiano, sancionado colectivamente.

Por el momento la comunidad prefiere la igualación organizativa (rotación como principio) antes que se incite la especialización y la diferencia explícita. Esto no significa que no haya líderes, que no existan diferencias y desigualdades, personas con mayores habilidades..., sino que la comunidad funda gran parte de su táctica en que -al menos a nivel comunitario- esas diferencias no se agranden ni expliciten: que la reciprocidad no ceda ante la presión de la lógica del intercambio. No se favorece así la diferenciación funcional entre sus habitantes ni la desigualdad de recursos entre las familias. Ese parece ser el secreto del éxito de esta "nueva" comunidad: la práctica centrípeta (asambleas, rotación) que contrarreste -al menos en parte- a la evidente tendencia centrífuga que animarían el mercado y el Estado globalizados a través de una actividad turística estandarizada y de políticas conservacionistas hegemónicas. Siguiendo a Temple (2003a), el caso de Agua Blanca nos permite ver cómo el turismo y su filosofía globalizada basada exclusivamente en el intercambio (individualismo, meritocracia, competencia, aumento de la desigualdad...) puede convertirse en práctica de reciprocidad a partir del 'límite en el provecho propio' gracias al desarrollo de interfases como el comité que organiza la actividad en la comunidad. Con todo ello resulta que el turismo organizado desde prácticas de rotación de oportunidades y obligaciones potencia el 'lazo social' sobre el exclusivo intercambio de bienes (Temple y Chabal 1995). 


\section{Reflexiones sobre la Vigencia de la Comunidad}

La práctica comunitaria (asambleas, rotación...) asumida como táctica (de Certeau 1990), fundamentación epistemológica (Bauman 2001) y expresión de reciprocidad (Temple 2003a), es la que hace posible la comunidad como forma de habitar la globalización. Su vigencia se asienta en tácticas de reciprocidad como la rotación, antídoto imposible de diferencias y especializaciones, factor de estabilidad para un sistema que amenaza constantemente con quebrarse por presiones externas e internas. Por su parte, la asamblea constituye un marco regulador, un ámbito comunicativo que busca horizontalidad más allá de las evidentes diferencias, conformando un contexto de gestión y gobierno socioambiental. La peculiar organización turística es reveladora del sentido de esta apuesta comunitaria que incluso comienza a cambiar rasgos bien definidos de las relaciones sociales, mostrándonos cómo la comunidad es realmente un proceso vivo, flexible, creativo y adaptativo, como lo ha sido históricamente (Arguedas 1987; Gundermann y Vergara 2009). El desarrollo turístico está empezando a socavar la tradicional dominación masculina: las mujeres adquieren cada vez más presencia a distintos niveles así como participación en actividades hasta ahora impensables (turismo, artesanía, e incluso comienza a plantearse su desempeño como guías...). Parece como si lo comunitario, tradicionalmente entendido como un espacio de sometimiento de género, pudiera dar pie -por acentuación de su práctica- a una matización de este tipo de desigualdades. Durante mi trabajo de campo pude comprobar una participación cada vez más activa de las mujeres en las asambleas, al punto de que en 2008 una de ellas ocupó por primera vez la vicepresidencia de la comunidad. Todo ello no está en contradicción con lo comunitario, sino todo lo contrario.

Los miembros de la comunidad son plenamente conscientes de las dificultades de sus tácticas, pero marcan con ellas un horizonte que funda lo comunitario a contracorriente -en ciertos aspectos- de las pautas del mercado y del Estado. Y es aquí donde la perspectiva de la reciprocidad propuesta por Temple (2003a) se nos revela en toda su capacidad analítica. La comunidad propicia antes el reparto de oportunidades que la competitividad interna. Y esta táctica -para nosotros paradójica- es la que mejor sirve a la competitividad de la comunidad en el mercado, especialmente el turístico. ¿Cómo de otra forma podría habitarse este territorio? Por su parte, el discurso de representación comunitaria se sitúa en otra esfera; forma parte del exterior de la comunidad más que de su propio interior; es igualmente necesario, aunque no suficiente: sitúa a la comunidad en una posición privilegiada ante el Estado y las organizaciones externas, pero no garantiza su funcionamiento interno.

Clastres (1997) nos hablaba de la "totalidad" y "unidad" de las comunidades. La totalidad se construye sobre la dependencia/autonomía respecto al exterior; la unidad en torno a la diferenciación/ cohesión interna. Es evidente que ambos procesos siempre son inacabados. La comunidad, como toda construcción discursiva, es "necesaria e imposible" para sus miembros (Laclau 1996): necesaria porque la cohesión es vital para la supervivencia individual, imposible porque la cohesión e igualdad interna que anuncia simbólicamente son inalcanzables. Del mismo modo, como práctica, es inconclusa: las actitudes y acciones no cristalizan completamente sino que habitan la tensión entre intereses contrapuestos, constituyendo un contexto eminentemente contradictorio (lo colectivo y lo individual, el intercambio y la reciprocidad). Esta doble naturaleza discursiva-práctica de la comunidad (que recuerda la de onda-corpúsculo de la luz) marca su realidad dinámica y procesual: la comunidad es tanto relato como acción sin fin.

No obstante, el caso analizado sugiere que mientras las prácticas dan un sentido táctico a la comunidad -planteando una alternativa de funcionamiento a la vida fuera de ella-, su construcción simbólica sugiere más bien una adaptación, una reproducción de la representación que el mundo global hace de lo indígena y de la naturaleza a través de políticas de conservación y desarrollo turístico. Por eso no podemos caer en la tentación de reducir la comunidad a su vertiente simbólica.

Evidentemente Agua Blanca no es un caso generalizable, pero sí un contexto significativo para reflexionar sobre las condiciones de producción/reproducción de lo comunitario en nuestro mundo global y su relevancia a distintos niveles. La importancia de estos agrupamientos humanos para el mantenimiento de la biodiversidad en distintas zonas del planeta es indiscutible (Moran 2006; Ostrom 2009). Por otra parte, su particular devenir muestra que la comunidad sigue teniendo plena vigencia como alternativa, como apuesta de 
un grupo de personas que quieren vivir con cierto margen de soberanía entre el mercado y el Estado. La comunidad se antoja en un equilibrio frágil e inestable, con una autonomía interna directamente proporcional a la dependencia externa: l'autonomie dépendente (Morin 2001:309).

Agua Blanca emerge sobre un territorio con fuertes restricciones ambientales, gobernado por un parque nacional; asimismo está amparada teóricamente por una legislación estatal que protege a las comunidades. Contra el Estado y al mismo tiempo favorecida por éste; frente a la protección ambiental pero practicándola; contra las injerencias del mercado pero plenamente inserta en él. Todo ello desarrollado en los últimos decenios. Múltiples paradojas sobre las que sólo arrojan luz las prácticas comunitarias en tanto claves para habitar un territorio disputado. En este sentido debemos entender el desarrollo táctico de prácticas a contracorriente -asamblearismo y rotación, entre otras- para navegar en la globalización; prácticas negadas en los espacios hegemónicos, pero con plena vigencia en los contrahegemónicos. Como hemos visto, estas prácticas alumbran formas alternativas de comunicación y relación social, de control y gestión del territorio, de regulación del uso de los recursos y de autoorganización de actividades, con todo ello fundan un tono particular para la vida en común. Por tanto, este tipo de análisis bien podría extrapolarse a otros contextos en los que se pretenda ensayar formas colectivas de gestión de recursos, propiedades comunales e incluso experiencias cooperativas y de economía social. En general, este caso nos sugiere que la potenciación de otras lógicas complementarias a las hegemónicas (reciprocidad, formas de entendimiento común) no deben circunscribirse a ámbitos exclusivamente indígenas o 'ancestrales'.

Agua Blanca nos muestra el vigor de la comunidad como emergencia contemporánea. El comunitarismo no es exclusivamente esencia y ancestralidad, sino también práctica pragmática: forma organizativa para procurar una vida colectiva innovadora. Los grupos y territorios amenazados tienen en lo comunitario una estrategia política. De este modo, la comunidad debe conceptualizarse como coyuntura y analizarse más allá de su conformación simbólica para aterrizar en las prácticas que nos muestran su sentido cotidiano: la forma en que su población se inserta sobre el territorio concebido como socioecosistema (Berkes et al. 2003). Si los discursos reclaman ancestralidades, las prácticas muestran contemporaneidades; si bien los primeros se nos presentan de inmediato, las segundas aparecen más opacas a nuestra mirada (De Certeau 1990; Khon 2002). Todo ello nos invita a pensar que las prácticas comunitarias pueden ser innovación y vanguardia en vez de mera muestra de resistencia; perspectiva que quizá nos ayudaría a entender mejor algunos fenómenos comunitarios y cooperativos contemporáneos, alternativos al sistema neoliberal desde prácticas similares a las aquí estudiadas (Faulk 2008; Stephen 2005; Vargas-Cetina 2005).

La pervivencia de las comunidades en el entorno andino sigue siendo un objeto de estudio fascinante (Arguedas 1987; Gundermann y Vergara 2009; Korovkin 2002), máxime cuando se asocia a actividades tan globalizadas como el turismo y en contextos tan poco propicios como el de la protección ambiental. Godelier (2009) nos advierte que nuestro mundo está transformándose por dos movimientos en apariencia paradójicos y que pueden bien definir la globalización: la integración económica y la reafirmación de identidades locales. En medio de ello él propone analizar las formas de soberanía subyacente. La comunidad es una de estas formas de soberanía en tanto en cuanto parece capaz de navegar táctica y creativamente en la globalización.

Agradecimientos: el autor agradece a los revisores anónimos sus comentarios y observaciones que sin duda han contribuido a mejorar sustancialmente la versión final del artículo.

\section{Referencias Citadas}

Arguedas, J.M. 1987. Las Comunidades en España y el Perú. Instituto de Cooperación Iberoamericana, Madrid.

Bauman, Z. 2001. Community. Seeking Safety in an Insecure World. Polity Press, London.

Berkes, F., J. Colding y C. Folke 2003. Navigating SocialEcological Systems. Cambridge University Press, Cambridge.
Brint, S. 2001. Gemeinschaft revisited. Sociological Theory 19:1-23.

Castell, M. 1997. The Information Age. Blackwell, Oxford.

Chaiklin, S. y J. Lave (eds.) 1993. Understanding Practice. Perspective on Activity and Context. Cambridge University Press, Cambridge. 
Clastres, P. 1997 [1977]. Archéologie de la Violence. La Guerre dans les Sociétés primitives. L'aube, Paris.

Cohen, A. 1985. The Symbolic Construction of the Community. Routledge, London.

De Certeau, M. 1990. L'Invention du Quotidien I. Arts de Faire. Gallimard, Paris.

De Hart, M. 2009. Fried Chicken or Pop? Redefining Development and Ethnicity in Totonicapán. Bulletin of Latin American Research 28:63-82.

Faulk, K.A. 2008. If they touch one of us, they touch all of us: Cooperativism as a counterlogic to neoliberal capitalism. Anthropological Quarterly 81:579-614.

García Canclini, N. 1999. La Globalización Imaginada. Paidós, Barcelona.

Giddens, A. 2000. Runaway World: How Globalization is Reshaping our Lives. Profile Books, London.

Godelier, M. 2009. Communauté, Société, Culture. Trois Clefs pour Comprendre les Identités en Conflits. CNRS Editions, Paris.

Gundermann, H. y J.I. Vergara 2009. Comunidad, organización y complejidad social andinas en el norte de Chile. Estudios Atacameños 38:107-126.

Hernández Castillo, R.A. y R. Nigh 1998. Global processes and local identity among Mayan coffee growers in Chiapas, Mexico. American Anthropologist 100:136-147.

Hernández-Ramírez, E. y E. Ruiz-Ballesteros 2011. Etnogénesis como práctica. Arqueología y turismo en el pueblo Manta (Ecuador). AIBR Revista de Antropología Iberoamericana 6:159-192

Khon, T. 2002. Becoming an islander through action in the Scotish Hebrides. Journal of the Royal Anthropological Institute 8:143-158

Korovkin, T. 1997. Taming capitalism: The evolution of peasant economy in Northern Ecuador. Latin American Research Review 32:89-110.

- - - 2002. Comunidades Indígenas. Economía de Mercado y Democracia en los Andes Ecuatorianos. Abya-Yala, Quito.

Kuper, A. 2008. Changing the subject -about cousin marriage, among other things. Journal of the Royal Anthropological Institute 14:717-735.

Laclau, E. 1996. Emancipation(s). Verso, London.

McEwan, C., M. I. Silva, y C. Hudson 2006. Using the past to forge the future. The genesis of the community site museum at Agua Blanca, Ecuador. En Archaeological Site Museums in Latin America, editado por Helaine Silverman, pp. 187-216. University Press of Florida.

Martín Barbero, J. 2003. Oficio de Cartógrafo. Travesía Latinoamericanas de la Comunicación en la Cultura. Fondo de Cultura Económica, Santiago.

McNeish, J. 2002. Globalization and the reinvention of Andean tradition: the politics of community and ethnicity in highland Bolivia. Journal of Peasant Studies 29:228-269.

Michaux, J., M. Gonzáles y E. Blanco 2003. Territorialidades andinas de reciprocidad: la comunidad. En Las Estructuras
Elementales de la Reciprocidad, editado por D. Temple, pp. 75-96. TARI / Plural editores, La Paz.

Mignolo, W. 2002. Historias Locales / Diseños Globales. Colonialidad, Conocimientos Subalternos y Pensamiento Fronterizo. Akal, Madrid.

Moran, E. 2006. People and Nature. An Introduction to Human Ecological Relations. Blackwell, Oxford.

Morin, E. 2001. Le Méthode. L'Humanité de l'Humanité Seuil, Paris.

Nash, J. 1993. Crafts in the World Market: The Impact of Global Exchange on Middle American Artisans. State University of New York Press, Albany.

- - - 2001 Mayan Visions: The Quest for Autonomy in and Age of Globalization. Routledge, New York.

Niezen, R. 2003. The Origins of Indigenism: Human Rights and the Politics of Identity. University California Press, Berkeley, Los Angeles.

Ortiz, R. 2004. Mundialización y Cultura. Convenio Andrés Bello, Bogotá.

Ostrom, E. 2009. A general framework for analyzing sustainability of socio-ecological systems. Science 325:419-422.

Redfield, R. 1955. The Little Community. Almquist \&Wiksells, Stockholm.

Ruiz-Ballesteros, E. 2009. Agua Blanca. Comunidad y Turismo en el Pacífico Ecuatorial. Abya-Yala, Quito.

Ruiz-Ballesteros, E. y D. Solís-Carrión (coords.) 2007. Turismo Comunitario en Ecuador. Desarrollo y Sostenibilidad Social. Abya-Yala, Quito.

Ruiz-Ballesteros, E., M. Hernández, A. Coca, P. Cantero y A. del Campo 2008. Turismo comunitario en Ecuador. Comprendiendo el community-based tourism desde la comunidad. Pasos. Revista de Turismo y Patrimonio Cultural 6(3):399-418.

Ruiz-Ballesteros, E. y M.A. Vintimilla 2009. Cultura, Comunidad y Turismo. Ensayos sobre el Turismo Comunitario en Ecuador. Abya-Yala, Quito.

Safranski, R. 2005. How much Globalization can we Bear? Polity Press, Cambridge.

Stephen, L. 2005. Women's weaving cooperatives in Oaxaca. Critique of Anthropology 25(3):253-278.

Temple, D. 2003a. Teoría de la Reciprocidad (tres tomos). Padep-gtz, La Paz.

- - - 2003b. Las Estructuras Elementales de la Reciprocidad. TARI / Plural editores, La Paz.

Temple, D. y M. Chabal 1995. La Reciprocité et la Naissance des Valeurs Humaines. L'Harmattan, Paris.

Vargas-Cetina, G. 2005. Anthropology and cooperatives. From the community paradigm to the ephemeral association in Chiapas, Mexico. Critique of Anthropology 25(3):229-251.

Walsh, J. y S. High 1999. Rethinking the concept of community. Social History 32(64):255-273. 


\section{Notas}

1 Una reflexión en profundidad sobre la globalización excede las pretensiones de este artículo. Para una referencia plural al concepto remitimos entre otros a Castell (1997), García Canclini (1999), Giddens (1999), Martín Barbero (2003), Mignolo (2002), Ortiz (2004), Safranski (2005).

2 Bauman (2001) ilustra elocuentemente cómo el desarrollo del capitalismo desde sus orígenes constituyó un proceso de destrucción de lo comunitario del que la globalización no es más que una fase postrera.
3 Mayores de edad, dados de alta que pagan una cuota simbólica. Son los que tienen derecho a voto. Por cada familia hay al menos dos representantes. No hay límite más que la mayoría de edad. En un $75 \%$ son hombres. Según los registros consultados la presencia femenina está en franco aumento desde hace una década.

4 Korovkin (2002) señala explícitamente al consenso como forma tradicional de toma de decisiones en las comunidades andinas ecuatorianas. 
